\title{
Effect of Epinephrine Administration in Out-of-Hospital Cardiac Arrest
}

\author{
Ashish Kumar, MBBS; ${ }^{1}$ (1) Rajkumar Doshi, MD, MPH; ${ }^{2}$ Mariam Shariff, MBBS $^{1}$
}

1. Department of Critical Care Medicine, St John's Medical College Hospital, Bangalore, India

2. Department of Internal Medicine, University of Nevada Reno School of Medicine, Reno, Nevada, USA

Correspondence:

Ashish Kumar, MBBS

Department of Critical Care Medicine

St John's Medical College Hospital

Kormangala, Bangalore, India-560034

E-mail: drashishkumar.u@gmail.com

Conflicts of interest: Authors have nothing to disclose.

Keywords: epinephrine; out-of-hospital cardiac arrest; survival

Received: September 01, 2019

Accepted: November 11, 2019

doi:10.1017/S1049023X20000382

(C) World Association for Disaster and

Emergency Medicine 2020.
Kumar A, Doshi R, Shariff M. Effect of epinephrine administration in out-of-hospital cardiac arrest. Prehosp Disaster Med. 2020;35(3):351.

Sir,

We read with interest a meta-analysis published in Prehospital and Disaster Medicine titled "The Effect of Prehospital Epinephrine in Out-of-Hospital Cardiac Arrest: A Systematic Review and Meta-Analysis." ${ }^{\text {Th }}$ The authors included two randomized control trials totaling to 8,548 patients in the final analysis. We would like to congratulate the authors for their work. However, we have the following observation to make. Three studies titled: "Dynamic Effects of Adrenaline (Epinephrine) in Out-of-Hospital Cardiac Arrest with Initial Pulseless Electrical Activity (PEA)" by Nordseth, et al; "Intravenous Drug Administration During Out-of-Hospital Cardiac Arrest, A Randomized Trial" by Olasveengen, et al; ${ }^{3}$ and "High Dose and Standard Dose Adrenaline do not Alter Survival, Compared with Placebo, in Cardiac Arrest" by Woodhouse, et a $1^{4}$ were randomized control trials studying the effect of epinephrine administration on out-of-hospital cardiac arrest as compared to placebo. The authors have excluded these studies from the final analysis in the present meta-analysis. Since these studies have contradicting results, their inclusion in the final analysis may alter the final conclusion of the meta-analysis.

\section{References}

1. Ng KT, Teoh WY. The effect of prehospital epinephrine in out-of-hospital cardiac arrest: a systematic review and meta-analysis. Prehosp Disaster Med. 2019;34(5):532-539.

2. Nordseth T, Olasveengen TM, Kvaløy JT, Wik L, Steen PA, Skogvoll E. Dynamic effects of adrenaline (epinephrine) in out-of-hospital cardiac arrest with initial pulseless electrical activity (PEA). Resuscitation. 2012;83(8):946-952.

3. Olasveengen TM, Sunde K, Brunborg C, Thowsen J, Steen PA, Wik L. Intravenous drug administration during out-of-hospital cardiac arrest: a randomized trial. JAMA. 2009;302(20):2222-2229.

4. Woodhouse SP, Cox S, Boyd P, Case C, Weber M. High dose and standard dose adrenaline do not alter survival, compared with placebo, in cardiac arrest. Resuscitation. 1995;30(3):243-249. 